\title{
Teaching English in Multilingual Classrooms of Higher Education: The Present Scenario
}

Prem Prasad Poudel

\begin{abstract}
This article aims to discuss some of the major challenges emerged recently in the muItilingual classes in higher education of Nepal. For this, I sampled 20 teachers from four campuses of Kathmandu valley. Similarly, 30 students were selected from those campuses. A set of separate questionnaires was distributed for both teachers and students and at the same time the classes of the teachers were observed. I conducted focus group discussions to elicit the real information from the informants. Major findings show that in the classes of higher education, neither the teachers nor the students are satisfied with the use of medium of instruction. There are communication problems, content delivery problems, comprehension related problems because of language gaps. Finally, in this article, some suggestions are made to make English language teaching in the multilingual settings more effective.
\end{abstract}

Key words: Multilingual classroom, multiculturalism, medium of instrcution, multilingual education

\section{Background}

Nepal is a multicultural, multiethnic and multilingual country. Because of its geopolitical uniqueness, it has been a place for multi-faceted research studies for the scholars from all around the world. The population census of 2001 has listed 92 identified languages and the other unidentified languages. Similarly, successive research studies carried by various researchers claim that there are more than 126 languages. Most of these languages do not have their written scripts so the Government of Nepal has launched some initial programmes for the protection of the languages as they are a part of cultural heritages of the country. The protection of the languages has been one of the political agendas of the political parties of Nepal and sometimes there emerged protests for the recognition of their indigenous languages and the establishment of an inclusive language policy in the newly established republic of Nepal. The mother tongue education policy of the state is one of the consequences of the multilingual status of this country. For this education, textbooks have been written in more than 17 different languages by the Curriculum Development Center. Recently, the government of Nepal has prepared 'Multilingual Education Implementation Directory, 2010'. This has endorsed a policy for recruiting a native-speaker teacher of the local language in each school (MOE, 2010). From the pedagogical perspective, it has been very challenging both for the teachers and learners in our school level. In the same background, there have been very few discussions on how to settle or address the multilingual classroom challenges in higher education of Nepal.

Multilingualism refers to the condition in which more than two languages are used in the same setting for similar purposes. It has been one of the characteristics of modern civilization. But it is still a matter of debate just how much proficiency is required to get mastery over languages. Many linguists define bilingualism/ multilingualism as 'mastery over two/more languages...', but they are not clear on what level of mastery makes competence in grammar, vocabulary, communicative function, etc. The 
multilingual context has brought many issues which may be sometimes the complications for the sociolinguists. For example, in isogloss areas, a hybrid type of language may be created among people from various linguistic backgrounds. One of the prominent questions which the sociolinguists are trying to answer is-What are the consequences of multilingualism concerning all sorts of domains of society involving language, such as language education (language teaching) and the judiciary? It is generally accepted that language is an important marker of identity. But what is the national, regional or ethnic identity of people living in the multilingual contexts? What are the consequences of mobility and migration in the union for multilingualism? What different educational impacts are due to multilingualism? A number of social complexities are witnessed. For instance, frequent code-switching is highly probable. As a pedagogue, I have observed language teachers and language learners switching their code inside the classroom . There may be various purposes for code-switching. Holmes (2008) writes that a speaker may switch to another language as a signal of group membership and shared ethnicity with the addressee. In this context, language is a carrier of ethnic identity and culture. This creates multiculturalism even inside the classroom.

\section{Linguistic diversity and multiculturalism}

The world is a storehouse of languages. There is linguistic diversity. Linguistic diversity reflects the existence of the multitude of languages spoken in the world which is variously estimated. Crystal (2009, p. 3) writes "most reference books published since the 1980s give a figure of between 6000 and 7000 , but estimates have varied in recent decades between 3000 and 10,000." Safeguarding this diversity today is one of the most urgent challenges facing our world. Estimates suggest that at least half of them are in danger of disappearing in the coming years. While some countries are linguistically homogeneous, such as Iceland, many countries and regions display a wealth of linguistic diversity, for example, Indonesia, with over 700 languages and Papua New Guinea with over 800 languages. The actual distribution of linguistic diversity is uneven. Over
70 percent of all languages in the world are found in just 20 nation states among them most of them are the poorest countries in the world. Regarding the same, Crystal (ibid. pp.10-11) writes "I will opt for the range of between 5000-7000 as my lower and upper bounds, for the year 2000-6 $\pm 1 \mathrm{~K}$." In general, bilingual and multilingual contexts (that is the presence of different linguistic groups living in the same country) are the norm rather than the exception through the world, both in the North and the South. Bilingualism and multilingualism, that is, the use of more than one language in daily life, will be normal practice in this context (UNESCO, 2003). Linguistically diverse contexts cover a range of scenarios in the globe. Broadly speaking, however, these correspond either to more traditionally diverse situations where several, or even up to many hundreds of languages have been spoken in a region over a long period of time, or to more recent developments particularly, in urban concentrations, the result of migratory phenomena, where in some city schools there may be as many as 30 or 40 different mother tongues among students. In all cases, there is a need to take into consideration the specific learning needs of children in relation to the language or languages of the home and those of the school. The multilingual situation is a result of migration, movement of people after the World War II, spread of colonial power, the volunteer programmes, travel and tourism, etc. In multilingualism, moving from one language to another in the course of a single conversation is very common; sometimes people may not know consciously when they move from one language to another.

Wardhaugh (2000) regards monolingualism as a misfit. Therefore, it is obvious that in many of the countries multilingualism is a normal phenomenon for daily living and it is a requirement in this modern world. A speaker is forced to use different languages in different situations; for example s/he has to use one language at home, another at school or sometimes another in trade or other daily professional situations (organizations). In the place where such situation is present, the individuals learn (acquire) language naturally or unconsciously, and we can sometimes observe the language shift.This is why a child growing up or brought up in a bilingual/ multilingual society automatically becomes multilingual. 
Sometimes multilingual and multidialectal become confusing. Multidialectal is such a situation in which a person understands (speaks) more than two varieties of the same language. For example, in Nepal, a Nepali language speaker may be called multidialectal if $\mathrm{s} /$ he can speak the eastern, western and far western variety of Nepali language. Sometimes socio-cultural practices invite multilingual situations like the marriage system in Tukano community where the husband and wife should speak the separate languages of their own. In that situation a newly born child becomes a multilingual by being exposed to father's language, mother's language and other's language spoken around them. There, multilingualism is taken for granted. Therefore, multilingualism is closely related to multiculturalism. The cultural richness of different ethnic groups may lead to multilingualism. By this type of complexity, there have been hot debates on language planning in states like Nepal. Maddox (2003, p.205) points out

If the language policy is to effectively tackle problems of social exclusion it must be reoriented from the current culturist concerns of nationalism and ethnicity, to a more pragmatic agenda that focuses on questions of utility and access. This necessarily involves a shift in the discourse of language rights, from a monolingual agenda revolving around the primacy of the mother tongue (Brass 2003), to a recognition of the pervasive multilingualism that exists in Nepal, the utility of local, regional, national and international languages.

Quite recently, The Interim Constitution of Nepal (2007), an outcome of the Andolan II, makes the following provisions for languages:

(1) All the languages spoken as the mother tongue in Nepal are the national languages of Nepal.

(2) The Nepali Language in Devanagari script shall be the official language.

(3) Notwithstanding anything contained in clause (2), it shall not be deemed to have hindered to use the mother language in local bodies and offices. State shall translate the languages so used to an official (The Interim Constitution of Nepal (2007), Part 1, Article 5)
This shows that there are some mandatory conditions provided by law. The allowance of local languages in the government offices and in the educational institutions is further strengthening multilingualism.

\section{Teaching multilingual versus monolingual classes}

Different types of papers have been presented on how the languages are positioned in the multilingual classrooms. The native languages of the classroom teacher play important roles in the classroom interaction. Teachers' beliefs and attitudes towards the native languages of students also determine the extent of their interactions. There may be silent conflict between the students of different languages. Similarly, even in the same classroom, the students may use different varieties of the same language when they speak in the presence or absence of their teachers. Deirdre Martin's (ref.??) report showed that the Punjabi speaking boys in one of the primary schools of India used English as the language of the classroom and they used Punjabi when teacher was absent. A similar condition could be found in most of the private schools of Nepal. The students use English as a language of interaction in the classroom in the presence of their teachers and they use Nepali or their mother tongue in the playground or when they are away from their teachers. They use cultural-specific interaction styles while addressing their individual friends. The following statement highlights the importance of this point.
When children are educated exclusively in a non-mother-tongue language, they are prevented access to education because of the linguistic, pedagogical, and psychological barriers created. Thus, these exclusively non-mother-tongue programmes violate the human right to education as expressed in the United Nations Convention on the Rights of the Child, among other human rights conventions. (Mishra, 2009)

Multilingual classes consist of students speaking different languages and are most often found in English speaking countries where students have come with an aim to learn English. Similar classroom conditions could be found in Nepalese 
schools also where students come to the class for learning English but are from diverse linguistic backgrounds. There are several major factors one must take into account when dealing with multilingual and monolingual classes. Students attending multi-lingual classes have come from different cultures, speak a different language and usually have no common language between them. Students attending a mono-lingual class are usually from the same background and speak the same language, allowing them to communicate amongst themselves in the classroom. This has its advantages and disadvantages. The advantages of attending multilingual classes are that students will be forced to speak English between themselves and with the teacher. Students speaking different languages will work at different speeds and can create divisions in the class. Hopefully the teacher is skilled enough to deal with these problems but if not, it can limit the more able students and/ or make the less able students feel stupid and cumbersome. This means an unskilled teacher in the multilingual classrooms will rather hamper than facilitate learning. Students from different backgrounds will also come across different problems in the English language, be it pronunciation, spelling or layout. These problems will be specific to each student and will take personal attention from the teacher. Explaining a problem of one student to the whole class may be ineffective as they don't necessarily experience the same difficulties. Again, with a less skilled teacher, the personal time taken to solve problems of an individual student could leave the rest of the class bored and neglected. The advantages of teaching monolingual classes are that the students are all on the same playing field, as they speak the same language, most would have similar cultures and most would experience similar problems when learning English. This gives the teacher an advantage as they generally don't have to deal with individual problems, any problem raised by one student would likely help the other students too. Students are able to intercommunicate using their mother tongue which can be a huge advantage in the classroom when the teacher sets an exercise for group work or pair work; the students are able to organise themselves together to carry out the tasks. It allows the lesson to run more efficiently. The disadvantages of teaching monolingual classes are almost the opposite to that of teaching multilingual classes. In the native country, students may often be in the class out of compulsion not out of want, which produces an environment of contempt, resulting in slow learning. Students communicating in their mother tongue can act as a hindrance as they are not practicing English in the classroom and very rarely outside the class, greatly reducing their exposure and practice of the language. Ultimately there are other factors such as preference of teachers and students, teacher experience and class objectives which may determine the success of a multilingual class. Awasti (2004, p. 3) points that "ambiguities and inconsistencies prevail between the multilingually oriented intentions of the state and monolingually dominated reality of the school. In the school system, the mother tongue of minorities seems to have been invisibilised and is seen as a handicap. As a result, the non-Nepali speaking students at the early stages of their schooling face exclusion".

As most of the teachers in Nepalese classrooms are dealing with the multilingual students. They must have experienced some of the common problems. It must be further challenging for them since most of the classrooms are large and heterogeneous. Because of linguistically plural classroom conditions even from basic level to the higher level, there seems to be a need for responding and inquiring this condition in order to help them to effective teaching. In the higher education of Nepal, there are large and heterogeneous classes and most of the teachers are bilingual (usually Nepali-native speaker teachers teaching English) and some of them are multilingual (usually other than Nepali native speaker teachers teaching English). My query here is that those teachers who usually deliver lecture in their classrooms must have felt somehow uneasy and similar conditions may have been felt by students of these classes. Finding out the real problems and their teaching strategies is one of the major goals of this research.

\section{Objectives}

The general objectives of the study were to present the overall scenario of English language teaching in multilingual classrooms. To be specific, the paper aimed to find out the following. 
- To identify the problems and challenges of multilingual classroom

- To find out how the teachers behave linguistically in the classroom while teaching English.

- To find out the reactions/attitudes of the students towards their teachers' use of language in the classroom and out of the classroom.

- $\quad$ To suggest some pedagogical implications.

\section{The methodology}

I sampled 20 teachers on the basis of judgmental sampling process. The teachers were selected from those who have been teaching English at the intermediate and bachelor levels at Tribhuvan University. The teachers were selected from Mahendra Ratna Campus, Saraswati Campus, Trichandra Campus and Rainbow International college of Kathmandu. A set of separate questionnaires were prepared for the teachers and the students. Along with the questionnaires, the classes of those teachers were also observed and notes were taken. Similarly 30 students were separately selected from those campuses and they were requested to fill in the questionnaire. At the end of the data collection process, a focus group discussion was organized in two campuses regarding the problems and challenges of multilingual classrooms. To validate the data, the triangulation was made among the teachers' responses in the questionnaires, their class observation and finally the focus group discussion activities. Finally an analysis was made on the basis of the data obtained. Since the questionnaire had both closed and open type of questions, the data were analyzed quantitatively and qualitatively. The major findings are stated below.

\section{Discussion and findings}

\section{Student's use of language in the classroom}

I found that majority of the students speak Nepali in the classroom even though the teachers were teaching through the medium of English (obtained from classroom observation). The medium of instruction was English but they interpreted in Nepali more frequently. Most of the students were found to be using the Nepali language to ask questions to teachers (out of 6 students asking question, only two spoke in English). The teachers explained or responded to the queries of students in both English and Nepali. This seems to be similar condition as found in the teaching of other subjects too other than language classrooms like Nepali Education classes.

\section{Teachers' use of language outside the classroom in the campus premises}

Regarding the question of teachers' use of language outside the classroom, it was found that almost all the teachers use Nepali as their primary language of interaction and English as the secondary language of interaction (they said that they feel more comfortable to use Nepali in interactions and use English in certain conditional interactions like if students ask questions in English only then they interact in English). A few teachers used their mother tongue to interact with those students whose mother tongue is similar to their language (for instance, a Tamang native speaker teacher of English rarely used Tamang language to interact with Tamang speaking students). Except English language teachers, other teachers used Nepali as the language of outside interaction. Some of the English language teachers used English as a medium of interaction in the campus premises.

\section{Students' use of language in peer groups}

The majority (out of 30 students in focus group discussion, 26 students responded that they use Nepali ) of the students used Nepali language as the language of interaction with their peers. Their responses revealed that even the students who are learning English as their major subject were found speaking Nepali during their interaction. Even in the classroom also, they interacted most of the time in Nepali. A few students were found using English for interaction in the pair. They responded that they feel comfortable using Nepali for interaction.

\section{Methods used in teaching}

Out of twenty teachers only sixteen teachers responded that they use different methods like 
lecture method, discussion and communicative method. Some of the language teachers used translation also. In a close classroom observation of these teachers, a few of them used the communicative method although most of them claimed that they teach using communicative method and discussion. From this I understand that what the teachers theoretically say and what they actually do in the classroom are largely different.

\section{Problems faced by Non-Nepali/ non-English speaking students in the classroom}

On the basis of the questionnaire and the responses of the teachers and students the following list of problems faced by the non-Nepali mother tongue speaking students is obtained.

- Communication related problems

- Interaction related problems

- Comprehension related problems

- Structural organization related problems

- Content delivery related problems

In the observation of the classroom condition, it was found that a few students could interact with the teacher regarding the content that the teachers were teaching. Those students who had Nepali as the mother tongue dominated the class. This has occurred may be because they felt more comfortable to say something in English and Nepali. For those students whose mother-tongue was other than Nepali hesitated to interact which would eventually lead them to obtain the bad results.

\section{Teachers' difficulty in delivering the message}

Most of the teachers replied that they feel difficulty while delivering the content in front of the students with varied language backgrounds. While interviewed, they clearly mentioned that because of the gaps in the use of the words (in Nepali) and the students' poor English language backgrounds, they have been skeptical whether their students actually perceive what they mean. They claimed that this type of situation is always there in every class. The physical appearance of students which shows their varied language backgrounds and ethnicity strikes at the first instance or first encounter in the classroom. This type of condition leads them to code shifting while presenting their details of the topic.

From the class observation also, I found that the teachers frequently translated and shifted into another language. They also exhibited some degree of hesitation while delivering the content. Whenever a non-Nepali mother tongue speaking student asked the question, then the teachers had to make deliberate effort to minimize the difficulty. In some of the cases the teachers were unable to understand the queries made by non-Nepali mother tongue speaking students ( for instance the speech of Urdu and Maithili speakers could not be easily perceived because those students were using the retroflex type of sounds). A few number of teachers tried to search for addressing the multilingual needs of the students. They claimed that though they could make reforms in classroom teaching methods, because of the setting of classrooms, varied or mixed ability students they had not been able to implement them further. The teachers suggested the following actions that could be used to address the students' multilingual needs. They were-

- Discussion of problems with other fellow teachers

- Formation of peer group of students with the same language background

- Preparation of multilingual materials

- Using examples from many languages, drawing typical expressions from the students who speak other than Nepali language as their mother tongue.

- Providing translation type of home assignment for the students.

Though they suggested the above mentioned activities, I found that the group work/pair work activities were rarely conducted by these teachers may be because there are some other technical and non-academic difficulties.

Understanding from the side of the students it was found that they need to be provided with a number of opportunities for practicing contents in their mother tongue as well as in English 
so that they would be able to understand the local realities and think to correlate them to the wider or global understanding. There were some instances in which the teachers used different techniques to encourage the students use foreign/ second language in the classroom. The following are the ways they used for this purpose (as replied in questionnaires and got from classroom observation)

- Inviting students for group discussion

- Formation of language groups (if possible) in the large classes

- Inviting them to translation activities

- Asking simple questions about their casual activities

- Suggesting them with instrumental motivation.

Reflecting from the perspective of the students, most of them opined that they wanted to practice the English language together with their mother tongue. They said that they had difficulty in finding the equivalent translations in their own language which sometimes made them humiliated to study further.

\section{Students' achievement and their mother tongue}

As most of the campus classrooms of Nepal are highly multilingual, we have found varied groups of students in terms of their mother tongues. As the study consisted of 30 students from different language backgrounds, the researcher tried to analyze their mother tongue and the relationship of this with their academic achievement. From the analysis, it was concluded that the students who have non-Nepali mother tongue have lagged behind compared to their Nepali-language mother tongue counterparts in terms of their achievement at the academic level. There may be many other intervening factors for the poor academic achievement of the students speaking other than Nepali language, however the researcher concludes that one of the causes may be the language barriers for their attainment of the level that their counter parts have obtained. May be the Nepali language facilitates for them learning any subject because most of the reading materials are available either in English or in Nepali. Very few reading materials are available in their own mother tongues

\section{Monolingual teaching method or multilingual teaching method}

A question was asked whether monolingual teaching method was to be used in the University level classes or multilingual teaching methods should be used there. In this connection, most of the teachers responded that there should be multilingual teaching methods because only when the students get exposure in their own language then they will be able to grasp the real meaning of the concepts or information. Fifteen teachers out of twenty were in favor of multilingual teaching and only five teachers opined that for getting command in only one language (English) the teaching should be done in it only and this is also beneficial for the global opportunities and access of the students. For them the another cause for using monolingual teaching is that very few teachers are available who could speak at least three languages. The teachers responded that the use of mother tongue and translation is also necessary for the successful delivery of the content. They felt that the students always try to understand the new concepts through their mother tongue. A virtual type of translation already takes place in their mind.

Similarly many of the students replied that they wanted the type of teacher who speaks many languages and could translate the words or the content meaning into their own language. In this regard they thought that this condition will encourage them to learn further and their linguistic diversity will be maintained. Almost all the students replied that only a few teachers exemplify in their mother tongues. So they sometimes feel difficulty in understanding the content. They reported that they feel happy whenever their teachers shift into their mother tongue either from the Nepali or English. Use of learners' mother tongue would be better for them to address the classroom conflicts between the students and teachers also.

\section{Conclusion}

From the study of the multilingual classroom situation of higher level education, the researcher 
came to the conclusion that even at this level, the students are deprived of the convenience to the right to get education in their own language. The teachers felt comfortable in Nepali and the students also felt comfortable in their own language but the goal of teaching is to make them competent in English. English language teaching situation seems to be affected by this situation also. The success in ELT also depends on the students' motivation towards it and the interference of learners' mother tongue seems to be one of the factors for poor performance in English. Because of the multilingual backgrounds of the students, it is very difficult for the teachers to devise the right type of teaching methodology. The appropriate method is that method which better fits in the particular classroom of the teachers. The orientation towards multilingual teaching methods is urgent for the present time to satisfy the students needs and to trigger the rapid growth of multilingualism in this twenty first century.

Prem Parsad Poudel is a faculty at the Department of English Education, Mahendra Ratna Campus, Tahachal, Kathmadu. He is a life member of NELTA.

\section{References}

Awasthi, L. D. (2004). Exploring monolingual school practices in multilingual Nepal. Unpublished Ph.D Thesis, Danish University of Education, Copenhegon.

Crystal, D. (2004). The language revolution. Cambridge: Polity Press.

Holmes, J. (1992). An introduction to sociolinguistics. London: Longman.

Mishra, M. K. (2009). Multilingual education: Indian folklife. Journal of National Folklore Support Centre. Series 22, April 1.

MOE. (2010). Multilingual education implementation directory. Kathmandu: MOE.

UNESCO. (2007). Advocacy kit for promoting multilingual education: Including the excluded. Programme Implementers Booklet. Bangkok.

Wardhaugh, R. (2000). An introduction to sociolinguistics. Oxford: Basil Blackwell.

Yadav.Y.P.(2009).Proposing useoflanguagein primary education in federal Nepal. $\mathrm{N}$ a $\mathrm{t}$ i o $\mathrm{n}$ a 1 symposium on Federalism and Education. Kathmandu, Nepal.

\section{Appendix- I:}

\section{Questionnaire to the teachers}

1) Your home language/s:

2) Other languages you know besides your home language/s (rank them in order of your proficiency):

a)

b)

c) .

3) What subject(s) do you teach at present? 
4) In general what language do you feel most comfortable to use?

5) What language/s do you use while teaching in the class? (Put in order of the degree of use)
a)
b)
c)

6) What language/s do your students use to speak to you in the class?

7) What language/s do you use to speak to your students outside the class?

8) What language/s do your students use to speak to you outside the class?

9) What language/s do your students use in peer groups?

10) Which method do you normally use in the class during teaching?
a) Lecture method
b) Discussion $\backslash$
c) Communicative $\backslash$
d) translation

11) What problems do you think non-Nepali/non-English speaking children face in your classroom?
a)
b)
c)
d)

12) Do you discuss the problems with the students or other fellow teachers?

Yes

No

Sometimes

13) How do non-Nepali speaking children perform in the class as compared to Nepali speaking children? (Tick an appropriate answer)
$\square$ as well as Nepali speaking children
$\square$ better than Nepali speaking children
$\square$ not as well as Nepali speaking children
$\square$ lag far behind the Nepali speaking children

14) Do you feel difficulty conveying your message in front of the students with varied language backgrounds?

15) What methods do you mainly use in the class while teaching the following subjects? 


\begin{tabular}{|l|l|l|l|l|l|l|}
\hline Methods & $\begin{array}{l}\text { Mother } \\
\text { Tongue }\end{array}$ & Nepali & Maths & Social St. & Sc. \& Env. & English \\
\hline & $\begin{array}{l}\text { (Tick in } \\
\text { one) }\end{array}$ & $\begin{array}{l}\text { (Tick in } \\
\text { one) }\end{array}$ & $\begin{array}{l}\text { (Tick in } \\
\text { one) }\end{array}$ & $\begin{array}{l}\text { (Tick in } \\
\text { one) }\end{array}$ & $\begin{array}{l}\text { (Tick in } \\
\text { one) }\end{array}$ & $\begin{array}{l}\text { (Tick in } \\
\text { one) }\end{array}$ \\
\hline Lecture method & & & & & & \\
\hline Translation method & & & & & & \\
\hline Discussion method & & & & & & \\
\hline Communicative method & & & & & & \\
\hline Project method & & & & & & \\
\hline Other methods & & & & & & \\
\hline
\end{tabular}

16) What actions have you taken to address their needs? (Tick the appropriate answer.)

(a) $\square$ I have formed peer groups of children with the same language background.

(b) $\square$ I have prepared sets of materials in their home language.

(c) $\square$ I have conducted bridge courses first and then put non-Nepali speaking children together with Nepali speaking

(d) $\square$ I have discussed the problems with other teachers.

(e) $\square$ Others

17) Do you encourage students to speak their home language/s in collegeschool?

$\square$ Yes $\square$ No

18) If yes, what steps have you taken to encourage them to speak their home language/s?
a)
b)
c)
d)

19) Do you think that use of learners' language in the class is necessary at the university level too?

20) What should be done at the university level to promote the learning of non-Nepali speaking children?
a)
b)
c)
d)

21) What do you think about the use of monolingual teaching methods against the multilingual teaching methods?

22) Do you use the multilingual textbooks in the classroom while teaching your subject?

23) Do you think that new teaching methods are to be adopted specially designed for the multilingual classes? 


\section{Appendix-2:}

\section{Questionnaire for students}

Name:

Mother tongue:

Subject:

Level:

1. Which is your level of qualification in the previous level?
a) First division
b) Second division
c) Third division

2. What language do you use in your daily life like home, playground, in casual conversation?

3. What medium of instruction is used in your classroom?
a) English
b) Nepali
c) Others(specify)

4. Do you feel difficulty with the language of instruction other than your mother tongue?
a) Yes
b) No
c) Sometimes

5. Does your teacher frequently translate into your language?
a) Yes
b) No
c) Sometimes
d) Frequently

6. Does your teacher exemplify in your mother tongue? If yes, how often?
a) Always
b) Sometimes
c) Never

7. How do you feel if s/he shifts to your mother tongue?

8. Do you want to be taught in your own mother language at the college level?

a) Yes

b) No 
9. Do you feel like you are discouraged in the classroom not being a Nepali language native speaker or English language native speaker?
a) Yes
b) No

If yes, why do you think so?

10. Do you have a fear of negative evaluation that could take place in terms your language background in your classroom?

11. How often do you interact in the classroom?
a) Always
b) Never
c) Frequently
d) Sometimes

12. How do you think the classroom problems generated by linguistic diversities can be solved?

a) Training the teachers in many languages

b) Developing parallel classroom materials

c) Teaching through translation

d) Students should forget about their mother tongue at the college level

Do you have a fear of negative evaluation that could take place in terms your language background in your classroom?

How often do you interact in the classroom?

Always

Never

Frequently

Sometimes

How do you think the classroom problems generated by linguistic diversities can be solved?

Training the teachers in many languages

Developing parallel classroom materials

Teaching through translation

Students should forget about their mother tongue at the college level 
Appendix-3

\begin{tabular}{|c|c|c|c|}
\hline SN & STUDENTS' ID & LANGUAGE & ACADEMIC ACHIEVEMENT \\
\hline 1 & $\mathrm{S1}$ & Nepali & Ist division \\
\hline 2 & S2 & Magar & Ist division \\
\hline 3 & s3 & Nepali & 2nd division \\
\hline 4 & S4 & Nepali & 2nd division \\
\hline 5 & S5 & Nepali & 2nd \\
\hline 6 & S6 & Nepali & Ist \\
\hline 7 & s7 & Gurung & 2nd \\
\hline 8 & 58 & Newar & Ist \\
\hline 9 & 59 & Newar & 2nd \\
\hline 10 & $\$ 10$ & Tamang & 2nd \\
\hline 11 & S11 & Tamang & pass \\
\hline 12 & $S 12$ & Maithili & 2nd \\
\hline 13 & 513 & Maithili & pass \\
\hline 14 & $\$ 14$ & Magar & pass \\
\hline 15 & $S 15$ & Bhoipuri & pass \\
\hline 16 & 516 & Magar & 2nd \\
\hline 17 & $\mathrm{~S} 17$ & nepali & 2nd \\
\hline 18 & 518 & Tamang & pass \\
\hline 19 & $\$ 19$ & Nepali & 2nd \\
\hline 20 & $S 20$ & Theti (a variety spoken in Terai) & 2nd \\
\hline 21 & $S 21$ & Gurung & pass \\
\hline 22 & S22 & Newari & 2nd \\
\hline 23 & $\$ 23$ & nepali & $1 \mathrm{st}$ \\
\hline 24 & S24 & Chepang & 2nd \\
\hline 25 & S25 & Rai & 2nd \\
\hline 26 & 526 & Rai & pass \\
\hline 27 & S27 & Limbu & pass \\
\hline 28 & $S 28$ & Maithili & 2nd \\
\hline 29 & S29 & Nepali & 2nd \\
\hline 30 & 530 & Tamang & pass \\
\hline & & & \\
\hline & & & \\
\hline & & & \\
\hline
\end{tabular}

